\title{
EDITORIAL: A CIÊNCIA E SUA COMUNICAÇÃO COM A SOCIEDADE.
}

\author{
EDITORIAL: SCIENCE AND ITS COMMUNICATION WITH SOCIETY.
}

\author{
João Carlos Krause ${ }^{1}$
}

Em mais um ano atípico, a ciência segue sob ataque constante, através do negacionismo e do obscurantismo intelectual que ignora evidências científicas e o próprio método cientifico, encontrando sustentação em teorias e discursos conspiratórios.

Neste sentido, cabe a comunidade científica se manter alerta para a importância da constante comunicação com a sociedade e com a tarefa de combate a desinformação. Manter uma estreita comunicação com a sociedade em geral, divulgando a ciência é um papel da social da academia.

Assim, quando iniciamos mais um ano, é com imensa satisfação que a equipe editorial da ENCITEC disponibiliza a primeira edição de 2021, se mantendo firme no propósito da divulgação cientifica, levando resultados de pesquisas relacionadas a área de Ensino, cumprindo o papel crucial e de extrema importância de difundir conhecimentos nas áreas de ensino em Ciências, Tecnologia e Saúde.

Nesta edição, que abre o ano de 2021, pode-se encontrar Artigos Científicos, Relatos de Experiências e Produtos Educacionais.

O artigo de abertura, traz uma pesquisa sobre o programa de Mestrado Nacional Profissional em Ensino de Física (MNPEF) que teve início em 2013 com 21 polos. O trabalho pesquisou 230 trabalhos de conclusão oriundos da primeira turma do MNPEF, relatando uma análise de elementos intrínsecos relativos ao conteúdo temático: cerne da proposta didática, referencial (is) teórico (s) adotado (s), conteúdos de Física e público de aplicação do produto educacional. Os autores identificaram a prevalência de um formato característico para os enunciados analisados, indicando a influência do meio acadêmico no processo de elaboração para os trabalhos de conclusão.

O segundo artigo desta edição, aborda dados de natureza qualitativa e quantitativa de pesquisas empíricas buscando compreender a posição dos professores diante das TICs e do Whatsapp. Os resultados indicaram que os professores depositam grande esperança nas TICS sobretudo para deixar o ensino mais dinâmico e atrativo, sendo que alguns professores consideram as TICs como um recurso, enquanto que outros indicam que estas são uma metodologia de ensino. O Whatsapp aparece como a TIC mais utilizada pelos professores, com alto poder de inserção com fins educativos, que viabiliza o ensino de todos os conteúdos de

https://orcid.org/0000-0001-8674-9634. Doutor em Ciências - Física Experimental (IF-UFRGS). Editor ENCITEC e coordenador PPGEnCT (URI), Santo Ângelo, RS, Brasil. Avenida Universidade das Missões, 464. Bairro Universitário, CEP 98.802-470, Santo Ângelo, RS, Brasil. E-mail: krause@san.uri.br. 
ciências e biologia, especialmente para àqueles que necessitam de maior abstração, como Citologia e Microbiologia.

Na sequência, o terceiro artigo, apresenta uma pesquisa que teve como objetivo verificar se os aspectos representacionais e textuais, presentes como suporte nas questões na área de Ciências da Natureza, são determinantes no desempenho dos estudantes no ENEM. Para tanto, o estudo foi realizado por meio de análise estatística descritiva do desempenho em questões previamente selecionadas dos exames realizados nos anos de 2012, 2013 e 2014. Os resultados indicaram que os aspectos representacionais e textuais não se configuram como determinantes no desempenho escolar.

O quarto artigo desta edição, apresenta os resultados de uma revisão sistemática de literatura (RSL) que teve como objetivo observar e analisar de que forma a Educação Ambiental Crítica está sendo abordada na formação inicial e continuada de professores. A investigação analisou trabalhos publicados na Biblioteca Digital de Teses e Dissertações do Instituto Brasileiro de Informação e Ciências e Tecnologia, Banco de Teses e dissertações da Coordenação de Aperfeiçoamento de Pessoal de Nível Superior - CAPES e em revistas qualificadas na área de Ensino em A1, A2 e B1 entre os anos de 2000 e 2018. A pesquisa analisou 7.460 trabalhos, sendo que destes apenas 16 abordavam a temática de formação de professores, evidenciando a carência nas publicações a respeito do tema.

O próximo artigo, se dedica a um episódio da História da Química, a Alquimia, à qual não é dada a devida atenção por educadores, visto que, muitas vezes, professores e alunos desconhecem os caminhos que levaram à origem da Química. Diante desse contexto, o trabalho teve como objetivo apresentar a História da Alquimia desde sua origem em Alexandria. Através da historiografia, os autores buscaram recontar brevemente os aspectos históricos do conhecimento alquímico, por meio da utilização de fontes secundárias, sendo consideradas duas abordagens historiográficas a fim de compreender o contexto no qual esse conhecimento se desenvolveu. Os autores perceberam a escassez de material especializado acerca do assunto, 0 que, por sua vez, dificulta a elaboração de materiais mais aprofundados e destacam a necessidade de desenvolver pesquisas que abordem a Alquimia atrelada a aspectos históricos e filosóficos da Ciência.

O sexto artigo cientifico desta edição, usa o modelo de PCK de Ciências, proposto por Magnusson, Borko e Krajcik (1999), para compreender como um residente de Ciências da Natureza mobiliza o seu PCK na construção de uma sequência didática sobre as leis de Newton. O autor encontra que existe um forte conhecimento de conhecimentos de currículo e estratégias didáticas do residente foram fatores primordiais desta empreitada. Destaca, também, que o processo de construção de sequências didáticas aflora algumas deficiências formativas do residente, como, por exemplo, atreladas aos conhecimentos de avaliação de seus estudantes. Por fim, o autor sugere que cursos de formação inicial oportunizem momentos para o desenvolvimento do PCK de futuros professores de Ciências.

O ensino de Física também é tema do sétimo artigo, onde os autores consideram aspectos sobre como o ensino de Física contribui com a formação dos estudantes, proporcionando-lhes conhecimentos que lhes permitam a interpretação de fatos, fenômenos naturais e processos 
tecnológicos. O trabalho descreve uma pesquisa desenvolvida com o intuito de avaliar como uma sequência didática fundamentada em pressupostos construtivistas e num ensino por problematização, auxiliada por recursos digitais e atividades experimentais, contribui para o estudo de conteúdos da mecânica rotacional. A proposta foi aplicada a uma turma de professores de Física em formação inicial. A pesquisa de natureza qualitativa e participante permitiu reflexões que sugerem que: o uso das problematizações colabora na identificação dos conhecimentos prévios e na condução dos alunos para a tomada de consciência da necessidade de aquisição de um novo conhecimento.

O próximo artigo, discute a terminologia e a metodologia intrínseca a um experimento didático tendo como ponto de partida atividades frequentemente expostas em livros e sites didáticos, exemplificando situações em que atividades assumem caráter estritamente demonstrativo e/ou observacional. Os autores apontam diferenças contextuais e metodológicas entre diferentes procedimentos associados à prática investigativa e discutem as implicações para o processo de aprendizagem. Por meio de exemplos associados ao ensino de conteúdos de Física, Química e Biologia, os autores sugerem caminhos para que atividades de demonstração possam assumir um caráter desafiador e de maior complexidade para o aprofundamento da aprendizagem.

O nono artigo desta edição, traz como motivação a constatação do baixo número de graduandos em licenciatura em física no Brasil e se propõem a buscar respostas para a seguinte questão: quais são os fatores que influenciam o quadro em questão, que resulta em que apenas uma pequena parcela de universitários siga a formação docente em física? A metodologia adotada no trabalho foi a de análise de dados através da Análise Textual Discursiva (ATD) aplicada às respostas a um questionário contendo perguntas abertas e fechadas. Os participantes foram estudantes de graduação em licenciatura em física de uma universidade comunitária do Rio Grande do Sul, com ingresso nos anos de 2011 a 2018. Os autores concluem que os principais fatores são o interesse intrínseco dos participantes no que se refere aos conteúdos estudados nessa ciência, a aptidão cognitiva para aprendizagem dos mesmos conteúdos, e certa concepção de mundo relacionada à educação e à ciência.

Na sequência, o décimo artigo desta edição, apresenta uma análise dos resumos de artigos sobre o Estudo de Caso com o objetivo de aprender mais sobre o uso desta estratégia em aulas de Ciências/Química. A pergunta da pesquisa foi "Como se mostra o Estudo de Caso nas produções da Área de Ensino de Ciências?". Foram analisados artigos de revistas A1 a B2 na Plataforma Periódicos CAPES, com o escopo dedicado ao Ensino de Ciências/Química. Os textos foram analisados através da Análise Textual Discursiva (ATD). Da analise os autores definiram duas categorias. A primeira mostrou que o Estudo de Caso possibilita o trabalho com temáticas investigativas, que têm um problema como foco de estudo. A segunda categoria evidenciou a possibilidade do desenvolvimento de habilidades como a argumentação, por meio do uso de temáticas contextualizadas que buscam o fortalecimento do exercício da cidadania do aluno.

$\mathrm{O}$ décimo primeiro artigo, apresenta um estudo que teve como objetivo mapear e classificar, em pesquisas que abordam o ensino e aprendizagem de conceitos eletroquímicos, aspectos metodológicos, base teórica e principais contribuições para a área de Ensino de 
Química no Brasil. Foram selecionados 19 artigos entre quatro periódicos selecionados, cujos resultados obtidos revelam que a maioria das pesquisas são empíricas, com abordagem qualitativa e priorizam o Ensino Médio e Ensino Superior. Em relação às Bases Teóricas, as pesquisas pautam-se em teorias Cognitivistas, Teoria da Aprendizagem Significativa e Teoria Sociocultural. Por fim, os autores apontam as dificuldades de aprendizagem e estratégias remediativas das mesmas, destacando-se que a utilização de estratégias remediativas perpassa pela superação de visões simplistas das concepções de ciências, da natureza da ciência e de concepções de ensino e aprendizagem.

Na sequência, no décimo segundo artigo, os autores descrevem uma investigação com foco na compreensão do conceito de vetor campo elétrico por uma aluna do curso de Licenciatura em Matemática matriculada na disciplina de Física Geral III, por intermédio de uma simulação computacional no software GeoGebra. O objetivo foi investigar/identificar, de acordo com a Teoria da Mediação Cognitiva (TMC) as mediações (psicofísica, social, cultural e hipercultural) determinantes na aprendizagem de vetor campo elétrico. Os autores, a partir de gestos descritivos e suas correspondentes imagens mentais, realizaram as análises dos dados produzidos e concluíram a existência de indícios de que a mediação social, cultural e hipercultural estavam presentes na aprendizagem de vetores.

Fechando a seção de artigos científicos, o décimo terceiro artigo, discute a questão sociocientífica sobre bactérias e saúde para caracterizar dois modos de se conceber saúde e suas consequências para a educação em saúde e a formação dos cidadãos. Os autores argumentam que cada enfoque sobre a saúde pode ser considerado e adotado em diversos contextos educativos e para o alcance de diferentes objetivos de ensino e aprendizagem. Contudo, salientam que, é importante ter clareza desses modelos, sobretudo na atuação docente. Por fim, apontam algumas perspectivas para a melhoria da formação e da atuação de professores de ciências.

Abrindo a seção de Relatos de Experiências, o décimo terceiro artigo, apresenta o processo de elaboração de um produto educacional (sequência didática), desenvolvido a partir de uma formação docente para professores da educação básica na área de robótica educacional, a qual utilizou o Robô Cubetto e seus blocos de código programáveis em um processo de formação continuada de professores através da realização de oficinas de capacitação. Os autores, na perspectiva do trabalho, entenderam que a formação docente realizada permitiu aos professores a apropriação da tecnologia robótica e estes perceberam que esta tecnologia é capaz de atrair a atenção dos alunos nas idades iniciais e motivá-los a resolver problemas complexos, possibilitando um fazer educacional diferenciado através de uma prática pedagógica incentivadora.

O segundo Relato de Experiência desta edição, aborda a temática da avaliação em uma formação continuada com professores de Ciências do Ensino Fundamental da região do Alto Vale do Itajaí, Santa Catarina. Partindo do problema referente à questão da avaliação nos processos de ensino e aprendizagem em aulas de Ciências da Natureza, o relato teve como objetivo geral identificar quais as concepções sobre avaliação entre os docentes participantes. Ao longo do percurso formativo, os professores evidenciaram inicialmente concepções de 
avaliação voltadas para a noção de um instrumento avaliativo (prova, trabalho, relatório, seminário etc), enquanto noções mais amplas do processo foram manifestadas ao final do encontro. Tomando como base as perspectivas de avaliação de teóricos como Luckesi e Perrenoud, o autor trabalhou também com o referencial metodológico da Análise de Conteúdo, analisando as respostas dos professores a uma tempestade de ideias referente à temática avaliação, em que os participantes deveriam expressar sua concepção sobre o termo em uma palavra.

Encerrando esta edição, temos a seção de Produto Educacional com um artigo, que apresenta a análise de um percurso de assimilação de conhecimentos por licenciandos de química durante a resolução de questões acerca dos conceitos de metano e reações químicas envolvidos na produção de Biogás a partir da realização de uma atividade experimental. 0 experimento foi aplicado a estudantes na disciplina de Ensino de Química de uma Instituição de Ensino Superior de Pernambuco, Brasil. A análise dos dados foi feita a partir de aspectos da teoria da assimilação das ações por etapas de Galperin buscando identificar a forma e a qualidade das ações realizadas pelos sujeitos no processo de formação de conceitos científicos. Os resultados indicam que os licenciandos realizaram a ação de diferentes formas, e mostram níveis diferenciados de assimilação dos conceitos químicos trabalhados na resolução de questões, que foram evidenciados por meio das categorias graus de generalização, detalhamento e consciência.

Assim, fechamos mais esta edição e agradecemos a todos os autores pelas brilhantes contribuições e desejamos que estas possam servir de incentivo a novas iniciativas e que possam fomentar a qualificação permanente de pesquisadores e professores atuantes em todos os níveis de Ensino.

Esperamos estar à altura da confiança depositada em nosso periódico e esperamos que a leitura destes artigos seja revigorante a todos. 